\title{
O DISCURSO DO CONSUMO CONSCIENTE E A PRODUCุÃO DOS SUJEITOS CONTEMPORÂNEOS DO CONSUMO
}

\author{
Andresa Silva da Costa Mutz*
}

RESUMO: Discute-se, neste artigo, a constituição dos consumidores conscientes a partir do exame de enunciados que põem em circulação verdades relativas a um modo supostamente mais adequado de ser sujeito consumidor. Foram selecionadas as edições de um "Manual de Etiqueta" da revista Planeta sustentável, publicado entre 2007 e 2012, pela Editora Abril e distribuído na forma de encarte promocional. Realizou-se uma análise inspirada na teorização foucaultiana, com base na noção de discurso articulada aos conceitos de governo e poder. Os resultados indicaram que o discurso do consumo consciente se ocupa apenas com o controle de atos de compra segundo padrões desejáveis de consumo por indivíduo. O que faz dele muito mais um recurso de controle das condutas dos sujeitos de modo a manter em funcionamento o sistema econômico em vigor do que uma tomada de posição crítica ao modelo de consumo que tem causado prejuízos ao meio ambiente e à sociedade em geral.

Palavras-chave: Educação e Consumo; Consumo Consciente; Sujeito do Consumo.

* Doutora em Educação pela Universidade Federal do Rio Grande do Sul (UFRGS) e Professora Adjunta da Universidade Federal do Rio Grande (FURG)

Email: dessacost@yahoo.com.br 


\section{THE DISCOURSE OF CONSCIOUS CONSUMPTION AND PRODUCTION OF CONTEMPORARY SUBJECT OF CONSUMPTION}

ABSTRACT:This article discusses the formation of conscious consumers from the examination of statements that put in circulation truths concerning a supposedly more suitable mode to act as a consumption subject. We selected editions of an "etiquette manual" published as a part of the Sustainable Planet magazine, which was published between 2007 and 2012 by Editora Abril and distributed as a promotional booklet. It was carried out an analysis inspired by Foucault's theories, based on the notion of articulated discourse dialoguing with concepts of governance and power. The results indicated that the discourse of conscious consumption is only concerned with the control of purchase actions according to desirable patterns of consumption per individual. In other words, it is much more a tool for controlling subjects and keeping the functioning of economic system in place, than taking a critical stand regarding the consumer model that has harmed to the environment and societies as a whole.

Keywords: Education and Consumption; Conscious Consumption; Consumption Subject.

\section{INTRODUÇÃO}

Este trabalho é parte de uma tese de doutorado em fase de conclusão na qual investigo os modos como estamos produzindo e transformando nossa experiência como consumidores. Nele, procuro analisar como, na cultura contemporânea, tem-se constituído um tipo específico de sujeito do consumo - o consumidor consciente levando em conta a proliferação de convocações para que se exerça um consumo mais racional dos recursos naturais e econômicos. Pelo enunciado aprenda a comprar bem, para comprar sempre, somos convocados ao exercício de um consumo que, à urgência do uso consciente da água e da energia elétrica, por exemplo, apela também à necessidade do uso consciente do crédito e do dinheiro. Assim, quer se apresentem argumentos provenientes da área ambiental, quer se apresentem argumentos validados pela economia, prevalece a ordem discursiva do consumo consciente, que naturaliza certas verdades sobre nossos hábitos de consumo e prescreve a adoção de mudanças no cotidiano, com vistas à salvação das finanças, da sociedade, do planeta. 
Sublinho que as reflexões em torno do tema 'educação e consumo', apresentadas neste artigo, não foram motivadas por um desejo de definir o que é mesmo o consumo consciente e tampouco devem ser entendidas como a proposição de um modo mais adequado de educar para o consumo consciente. Estive ocupada, nesta investigação, com questões de outra ordem. Por isso, apresento uma análise que problematiza o discurso do consumo consciente, na medida em que saber e poder se implicam mutuamente, como um esforço de controle da população, que opera pela adequação das condutas dos consumidores, conforme modelos mais desejáveis ao sistema econômico vigente.

Para tal, realizei uma interlocução entre a teorização de Michel Foucault e as análises de Zygmunt Bauman em suas análises acerca do modo como estamos nos constituindo sujeitos em nosso tempo. Lancei mão de conceitos propostos por esses autores para entender o modo como os consumidores se tornam objeto do saber e as formas como os indivíduos são posicionados como sujeitos no interior das relações de poder implicadas pelas verdades do consumo.

Selecionei como material empírico os quatro Manuais de Etiqueta da revista Planeta sustentável publicados entre 2007 e 2012 pela Editora Abril. Eles são parte do chamado Movimento Planeta Sustentável - um projeto de comunicação multiplataforma que envolve revistas e sites da Editora Abril, sob um conselho consultivo composto por especialistas de diversas áreas - que tem a intenção de difundir a sustentabilidade. As bases do projeto parecem ser a publicação de matérias e campanhas nas revistas da editora, a realização de debates e palestras e a manutenção do site na internet contendo vídeos, resenhas, infográficos, simuladores, blogs, espaço kids, planos de aula e concursos de fotos.

Abordei esses manuais procurando dar conta de dois objetivos: a) descrever as representações do consumo que circulam por eles; e b) mapear os modos de intervenção sobre a conduta do sujeito consumidor ali prescritos. Em seguida, selecionei alguns excertos dos manuais, procurando problematizar os efeitos dos mesmos como um conjunto de verdades acerca do modo mais desejável de ser consumidor. Por fim, procurei relacionar os saberes implicados nesses modos mais "adequados" de ser consumidor às relações de poder que envolvem o ato de compra na sociedade contemporânea.

Os resultados da pesquisa apontaram o modo ambivalente como temos sido subjetivados para o consumo consciente. Uso o termo ambivalente - discutido por Bauman (1999) - para me referir 
ao fato de sermos convocados a exercer, a cada dia com mais vigor, nossa obrigação de consumir e, ao mesmo tempo e quase que com a mesma intensidade, sermos também ensejados a normalizar nossos hábitos de compra, tendo como modelo o imperativo do consumo consciente. Os procedimentos a serem adotados pelos sujeitos que aspiram a ser "bons consumidores" são, em sua maioria, ações que dizem respeito a atos de consumo.

Atrelados a eles estão princípios de equilíbrio, planejamento e uso da razão na hora da compra. Por isso, conclui-se que não se trata de exterminar ou diminuir o consumo, mas apenas de controlá-lo.

\section{REFERENCIAL TEÓRICO-METODOLÓGICO}

A pesquisa que deu origem a este artigo está alicerçada no pressuposto de que a cultura pode ser entendida como espaço de lutas por significação, o que implica admiti-la, também, como arena em que se estabelecem embates que envolvem relações de poder. Como explica Costa, "quem tem o poder de narrar o outro, dizendo como está constituído, como funciona, que atributos possui, é quem dá as cartas de representação, ou seja, é quem estabelece o que tem ou não tem estatuto de "realidade"' (COSTA, 2004, p.77). Por essa razão, proponho, neste artigo, uma análise interessada na produtividade pedagógica da cultura. Reitero que se trata de uma investigação adequada ao campo da Educação, porque, embora escape ao cotidiano formal escolarizado, possibilita o contato com outros espaços por onde circulam verdades e diz respeito à constituição dos sujeitos conforme modelos que nossa sociedade tem convencionado serem mais adequados e que vemos circular em narrativas presentes na internet, nas revistas, nos programas televisivos, enfim, nos diferentes espaços da cultura com que temos contato.

Amparada por Rose e Miller (2012), entendo governo como um conjunto de procedimentos que buscam representar determinadas populações e intervir sobre elas, conduzindo suas condutas em um horizonte possível de escolhas. "Governar, nesse sentido, é estruturar o eventual campo de ação dos outros" (FOUCAULT, 1995, p.245). Esse esforço de representação, próprio do governo, implica, neste artigo, uma análise focada no discurso. Afinal, "[...] o discurso não é simplesmente aquilo que traduz as lutas ou os sistemas de dominação, mas aquilo pelo que se luta, o poder do qual nós queremos nos apoderar" (FOUCAULT, 1996, p.10). Quanto aos 
investimentos que visam à intervenção sobre a população, centralizei a análise no modo como as tecnologias de governo alinham a economia e a conduta social aos objetivos sociopolíticos. A noção de tecnologias, conforme Rose e Miller, corresponde a

[...] mecanismos através dos quais autoridades de vários matizes têm buscado modelar, normalizar e instrumentalizar a conduta, o pensamento, as decisões e as aspirações dos outros, a fim de alcançar os objetivos que eles consideram desejáveis (ROSE; MILLER, 2012, p.46).

Sendo assim, uma análise do governo, nos Manuais de Etiqueta da Planeta sustentável, pressupõe tomá-los como a materialidade de um discurso que nos define como consumidores e que aciona "tecnologias" para nos subjetivar conforme o modelo desejável de conduta pressuposto pelo discurso do consumo consciente. Localizo os investimentos realizados pelo Grupo Abril em representar modelos mais adequados de consumo como um esforço de governo materializado na publicação dos manuais, afinal:

\footnotetext{
'Governar' [...] depende sempre de conhecimento, e os proponentes de diversos programas buscam fundamentar a si mesmos em um conhecimento positivo do que é preciso ser governado, formas de ponderar sobre ele, analisá-lo e avaliá-lo, identificando seus problemas e criando soluções (ROSE; MILLER, 2012, p.45).
}

No caso do meu objeto de pesquisa, o real programável ou as soluções para os problemas provenientes dos nossos hábitos, supostamente, inadequados de consumo apontam para o que temos chamado de consumidor consciente - aquele que aprendeu a comprar bem e vai continuar comprando sempre. Pelo menos, é isso que esperam dele os capitalistas. Acredito que o potencial político desta pesquisa resida justamente nesse ponto: a desnaturalização do consumo consciente como condição para salvarmos o planeta. Prefiro pensá-lo, antes, como pré-requisito para a salvação do sistema econômico contemporâneo.

\section{PROBLEMA E OBJETIVOS DA PESQUISA}

Inicialmente, preciso esclarecer que, neste artigo, estou considerando o discurso do consumo consciente em seus aspectos ambientais, sociais e econômicos. Tenho-o entendido como um 
conjunto de saberes atravessados e sustentados por relações de poder que nos educam para o consumo: não apenas para que consumamos mais, mas especialmente para que aprendamos a consumir "bem" e continuemos consumindo sempre. Esse "bem", do ponto de vista ambiental, implica a adoção de medidas para evitar o esgotamento dos recursos naturais planetários; do ponto de vista social, diz respeito à diminuição das desigualdades que dificultam a convivência entre grupos sociais distintos; do ponto de vista econômico, consumir "bem" envolve o cuidado no uso de nossos recursos financeiros pessoais de modo a preservar-se contra o superendividamento.

Assumir o caráter discursivo do consumo consciente implica reforçar sua contingência histórica e propor sua desnaturalização. É na cultura, conforme condições de possibilidade bem específicas, que damos sentidos às coisas pela linguagem. Por essa razão, tenhome perguntado acerca das condições de possibilidade que permitiram naturalizar-se - em uma sociedade intensamente convocada a exercer seu poder de compra através do consumo - um discurso que apela para o consumo consciente.

A fim de dar conta dessa questão, a partir dos materiais empíricos selecionados para este artigo, tracei como objetivos: a) apontar as representações daquilo que se entende ser um consumidor consciente nos Manuais de Etiqueta da Planeta sustentável; e b) mapear as prescrições que os manuais fazem aos sujeitos a fim de torná-los consumidores mais conscientes. Com Fonseca (2011), passei a entender essas representações e as intervenções implicadas na condução das condutas como um importante exercício de objetivação e subjetivação dos indivíduos que consomem e do qual decorre o processo de constituição dos sujeitos contemporâneosdo consumo. $\mathrm{O}$ autor destaca que:

Já se afirmou que tanto os processos de objetivação quanto os processos de subjetivação concorrem conjuntamente na constituição do indivíduo, sendo que os primeiros o constituem enquanto objeto dócil e útil e os segundos enquanto sujeito. Pode-se então dizer que o termo ‘sujeito' serviria para desig nar o indivíduo preso a uma identidade que reconhece como sua, assim constituído a partir dos processos de subjetivação. Esses processos, justapostos aos processos de objetivação, explicitam por completo a identidade do indivíduo moderno: objeto dócil-e-útil e sujeito (FONSECA, 2011, p.26).

Considerando que "todo e qualquer ato de consumo é essencialmente cultural" (BARBOSA, 2004, p.13), podem-se encontrar, então, na contingência histórica que possibilita o entendimento do 
consumo como um problema do governo no neoliberalismo, as razões para a proliferação de verdades que auxiliariam os indivíduos a fazerem opções responsáveis por meio da conscientização, governando-se à distância pelas escolhas dos cidadãos (ROSE, 2012).

Assim, alinho-me a Foucault quando afirma que se deve "considerar o consumo como uma atividade empresarial pela qual o indivíduo, a partir de certo capital de que dispõe, vai produzir uma coisa que vai ser sua própria satisfação" (FOUCAULT, 2008, p.311). A noção de consumidor como 'empresário de si', no interior da lógica neoliberal, permite pensar que, muito mais do que consumo, os atos de compra de um indivíduo são investimentos que ele faz sobre si e que operam na sua constituição como sujeito. Dialogo também com Featherstone (1995), que explica ter percebido um deslocamento da noção de consumo como valor econômico - marcado por princípios ascéticos em que se celebra a moderação e o gerenciamento da escassez - para uma outra concepção de consumo que, na contemporaneidade, tem posto em circulação "imagens de consumo com sugestões de prazeres e desejos alternativos, do consumo enquanto excesso, desperdício e desordem" (FEATHERSTONE, 1995, p.41). Segundo o autor, essas duas noções não se excluem, apenas se deslocam e se sobrepõem em movimentos decorrentes das demandas de cada sociedade. Assim, convivendo ambas,

[...] a cultura de consumo na atualidade não representa nem um lapso do controle, nem a instituição de controles mais rígidos; mas, antes, a corroboração dos controles por uma estrutura gerativa subjacente flexível, capaz de lidar ao mesmo tempo com o controle formal e o descontrole, bem como facilitar uma troca de marchas confortável para ambos (FEATHERSTONE, 1995, p.48).

Assim, à ampliação das práticas de consumo voltadas para a satisfação de prazeres e desejos se soma a evocação de valores como equilíbrio, racionalidade, planejamento. Todos marcadores sociais atribuídos a um tipo de sujeito de consumo, o consumidor consciente, que emerge estrategicamente em nossos dias e não noutros.

\section{MATERIAIS EMPÍRICOS E ENSAIO DE ANÁLISE}

A primeira edição impressa do manual é de 2007. Dois anos depois, somou-se a esta uma versão on-line disponibilizada para 
consulta em 2010 (a única a que tive acesso, pois o manual de 2009 não estava disponível no site do Movimento Planeta Sustentável). Em 2011, o guia foi ampliado e trouxe uma variedade maior de temas, além da versão eletrônica, apresentando o mesmo conteúdo do publicado em papel e alguns aplicativos para celular e tablets. A mais recente versão, a de 2012, também imprensa e on-line, apresenta temas ainda mais diversos do que as três anteriores. Aos tópicos comuns - água, energia elétrica e clima - outros foram incluídos, como biodiversidade, conferências mundiais e o tema da economia verde. O primeiro número do livreto registrou a maior tiragem da Editora Abril até aquele momento, chegando a 2,5 milhões de exemplares. $\mathrm{O}$ manual de 2011 também bateu recorde, com tiragem de 2,8 milhões.

Preciso esclarecer as razões que me levaram a tomar esses Manuais de Etiqueta da Planeta sustentável como fontes para uma pesquisa interessada no discurso do consumo consciente. As primeiras leituras me despertaram dúvida quanto à recorrência, nos quatro diferentes volumes analisados, de certas prescrições ligadas aos hábitos de consumo como meios de se alcançar uma conduta sustentável. Prosseguindo no trabalho investigativo, deparei-me com um documento publicado em 2006 pelo instituto AKATU, ${ }^{1}$ intitulado 12 Princípios do consumo consciente ${ }^{2}$. O que me chamou a atenção, nesse guia, foi sua similaridade com as orientações de conduta dos manuais publicados pela Abril, supostamente mais ligados à noção de sustentabilidade. A partir daquele momento, passei a tratar os Manuais da Planeta sustentável como guias de conduta que educam para o consumo consciente.

À visibilidade - expressa em número de exemplares publicados que os manuais alcançaram - se soma uma ampliação estratégica das temáticas de sustentabilidade e de consumo consciente, no interior da editora, para além do Movimento Planeta Sustentável. O conteúdo dos manuais também foi distribuído em pequenas porções inseridas como encarte publicitário nas revistas do Grupo Abril. Entre elas, a Exame, focada em negócios, carreira e tecnologias, e a Cláudia, interessada no público feminino. Acredito que essa proliferação do discurso do consumo consciente, em nome da sustentabilidade, em diferentes áreas do conhecimento, é uma estratégia de governo que, ao universalizar a temática do consumo consciente, acaba por naturalizar o próprio consumo.

Contribuem com esse argumento os resultados obtidos quando, ao me voltar aos manuais, procurei mapear as áreas do conhecimento implicadas na produção das verdades que por eles 
circulam. Em 2007, por exemplo, vemos citações, ao longo do texto, de autoria de um urbanista e ex-prefeito; outra de um ambientalista; duas de empresários; e uma outra formulada por um secretário de meio ambiente. Em 2010, como se trata apenas da versão em forma de teste, nenhuma citação direta apareceu. Em 2011, temos um convidado apenas, o navegador Amir Klink e, em 2012, os especialistas que participaram da edição, que são um engenheiro e um economista. Chamou-me a atenção essa diversidade de áreas do conhecimento que, por meio de experts convidados a falar sobre o tema da sustentabilidade, acaba reforçando a universalização do consumo consciente como suposta solução para o problema ambiental, o que, igualmente, contribui para sua naturalização.

Quanto às capas dos livretos, o ano de 2012 traz uma particularidade em relação às demais. Um mapa mundial serve como ilustração nessa edição e ocupa, inclusive, a contracapa. Ele é plano e não apresenta nenhum traçado de divisão política, física, climática ou demográfica. O que se vê é um conjunto de palavras comuns às temáticas do consumo consciente e da sustentabilidade, em diversos tamanhos e cores, distribuídas igualmente pelo mundo ali representado. ${ }^{3} \mathrm{O}$ que, a meu ver, também reforça a universalidade das questões ambientais. O manual sugere que, frente ao desafio da salvação do planeta, as divisões geopolíticas e todas as implicações culturais, econômicas e sociais que elas pressupõem seriam menos importantes, a ponto até mesmo de serem "deixadas de lado" no mapa.

Gostaria de destacar ainda outra particularidade do conjunto de materiais empíricos. Em relação ao manual de 2010, a interatividade que o modelo ou suporte tecnológico tornou possível merece ser considerada. "Você é sustentável?" - com essa pergunta inicia-se o teste. Todas as 120 questões do manual apresentam a mesma organização: trazem uma dica de sustentabilidade, indicam uma ação que contribuiria para combater os problemas ambientais, sociais ou políticos envolvidos naquele tema - que, em geral, remete a escolhas que envolvem o ato de compra e/ou descarte de algum produto - e encerram dando a opção ao leitor de assinalar sim ou não para a pergunta: "Você pratica essa ação?".

Entendo o teste do manual da Planeta sustentável como uma poderosa tecnologia de governo. Descrever o modo como nos tornamos consumidores, por meio de diferentes mecanismos de sujeição, entre eles o exame, significa aproximarmo-nos dos processos de subjetivação, entendido aqui como os modos ou 
as formas como produzimos e transformamos a experiência que temos de nós mesmos. Com Foucault (1991) aprendemos que tal processo se dá por meio da reflexão sobre si, na relação que estabelecemos com determinados aparatos de subjetivação. E em Larrosa lemos que a subjetivação dá conta da "relação do sujeito consigo mesmo" (LARROSA, 1994, p.38). É exatamente isso que o teste da sustentabilidade oportuniza: que o sujeito se coloque como objeto de sua análise. E, observando a si mesmo, diante de um modelo adequado de sujeito, que lhe serve como comparação, inspiração, motivação, espera-se que adote novos padrões de conduta como consumidor.

Minha segunda incursão de análise sobre os materiais resultou na organização de uma tabela em que procurei compreender o conteúdo de cada uma das edições do manual, estabelecendo também relações entre as publicações como parte de um conjunto ou série a que pertencem. Nesse momento, emergiram alguns achados que permitem relacionar os modos como se naturalizam as verdades ali apresentadas sobre sustentabilidade no interior do discurso de consumo consciente. 
Tabela 1 - Representação e intervenção como procedimentos de governo nos manuais de etiqueta Planeta Sustentável da Editora Abril

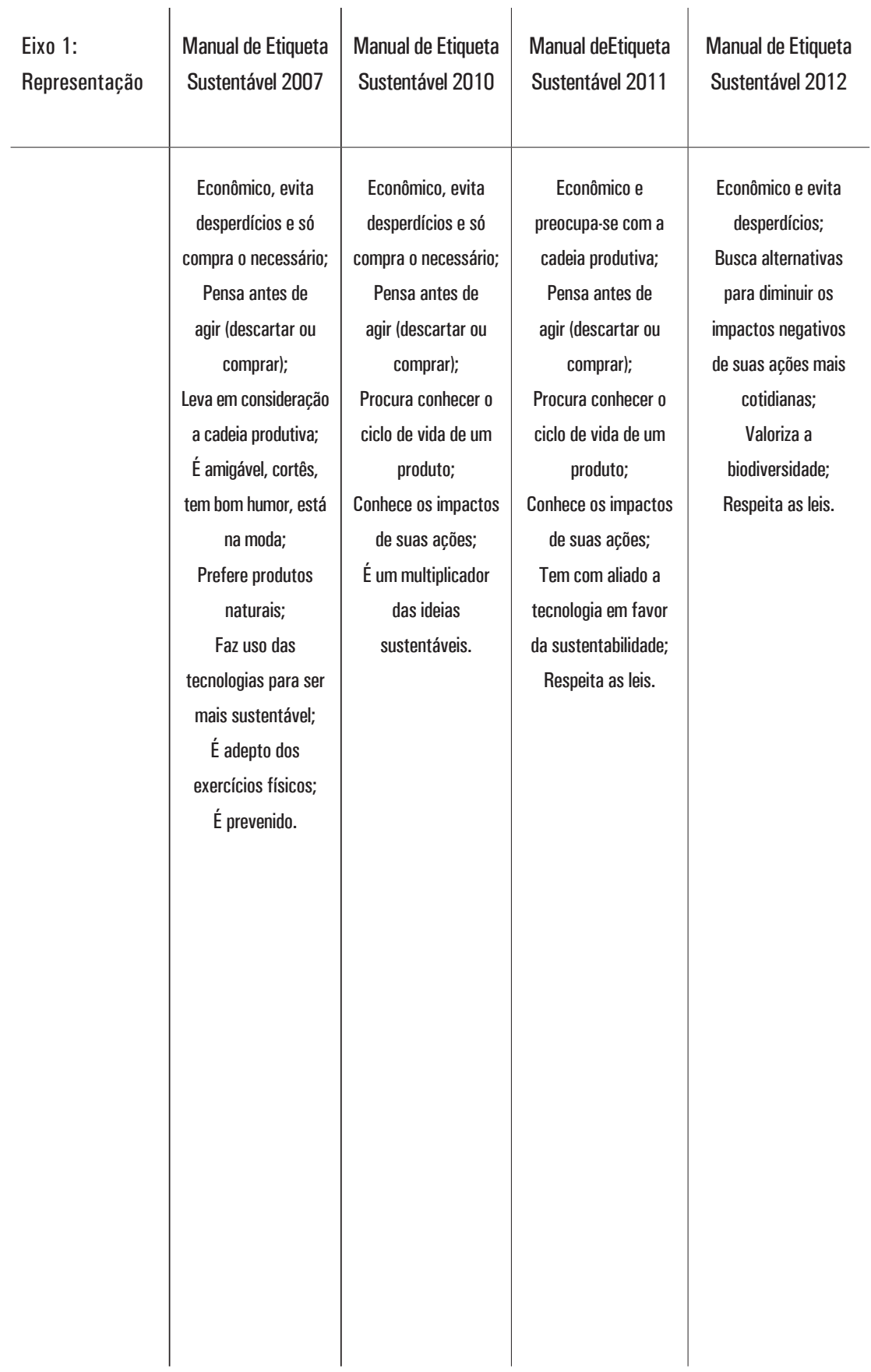




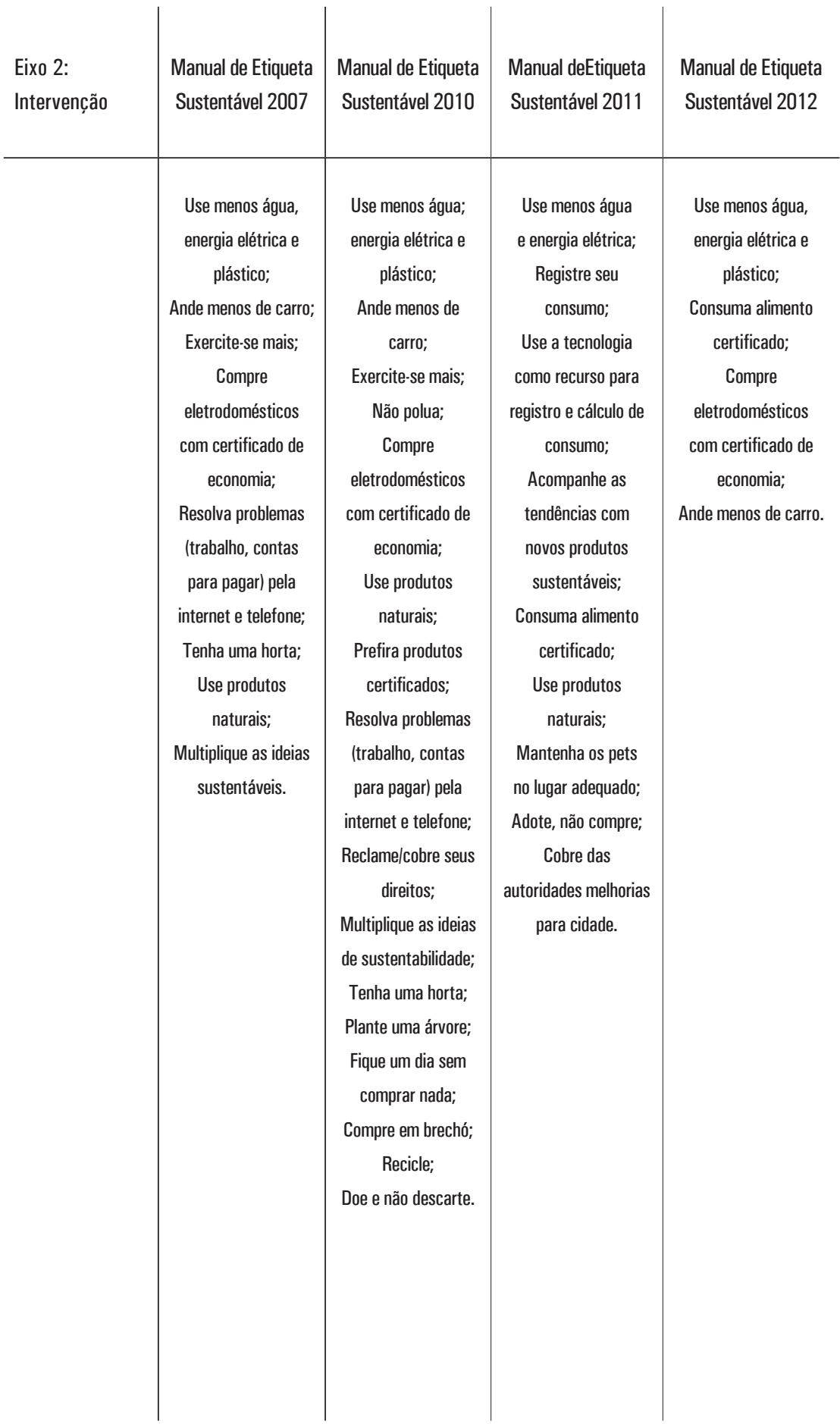


Os manuais são atravessados com intensidade pelo discurso do consumo consciente. A grande maioria das representações e prescrições encontradas dá conta de nossos atos de consumo, como se pode ver na tabela acima, e aponta para a constituição de um sujeito econômico, que pensa antes de agir, que mantém hábitos saudáveis de vida, que utiliza as tecnologias a seu favor, que procura estar atento ao ciclo de vida de um produto, que prefere produtos certificados e age como multiplicador das ideias em que acredita. Essa é uma lista de conteúdo "politicamente correta" e parece alinharse aos esforços por um planeta mais sustentável. Isso parece inegável. Mas fico me perguntando a respeito da lógica que ela pressupõe. Das relações de poder implicadas nos saberes ali constituídos. Isso pode nos levar a concebermos os manuais de outra maneira. Reparemos novamente nas listas da Tabela 1. As colunas foram construídas de modo que as representações (eixo 1) e prescrições (eixo 2) mais recorrentes nos manuais estivessem mais acima na tabela e as menos recorrentes mais abaixo, em cada um dos dois eixos de análise. $\mathrm{Na}$ linha que registra as representações do que seria considerado um "bom consumidor" (eixo 1), a qualidade que predomina é a economia. Ela é referida em todos os manuais analisados. Na linha relativa aos procedimentos a serem adotados pelos sujeitos que aspiram a ser "bons consumidores", verificamos que a grande maioria das ações promovidas pelos manuais diz respeito aos nossos atos de consumo. Atrelados a eles estão princípios de equilíbrio, planejamento e uso da razão na hora da compra. Diante disso, precisamos pensar: o argumento mais forte em favor da sustentabilidade é mesmo o econômico? Mas, ora, economizamos com que objetivo? Comprar mais. Em que medida comprar mais realmente coopera com nossos objetivos de educação ambiental?

Gostaria de sublinhar mais uma coisa que a tabela me permitiu pensar acerca do consumo consciente: que não se trata de exterminar ou diminuir o consumo, mas de apenas controlá-lo. Afirmo isso levando em conta a quantidade de objetos que somos instruídos a adquirir no manual com vistas a nos tornarmos mais sustentáveis. O manual de 2011 orienta para o registro de nosso consumo de água, luz e combustível a fim de evitarmos desperdícios e economizarmos mais. Também indica o uso das tecnologias, como aplicativos para celular, que nos auxiliam nesses registros. Com isso sou levada a pensar que o consumo consciente é muito mais um recurso de controle das condutas dos sujeitos de modo a manter em pleno funcionamento o sistema econômico em vigor, 
do que uma tomada de posição crítica ao modelo de consumo que, comprovadamente, tem causado tantos prejuízos ao meio ambiente e à sociedade em geral.

Enfim, na última etapa da análise, selecionei algumas unidades discursivas que emergiram durante a pesquisa, nomeandoas como liçoes de consumo que os manuais me permitiram aprender sob o seguinte enunciado: "Aprenda a comprar bem, para comprar sempre". Tudo muito familiar ao campo da educação escolarizada, diga-se de passagem: partindo de um sujeito "problema" - aquele que polui demais, gasta demais - esboça-se uma representação de conduta ideal para os sujeitos - os "consumidores conscientes" e, através de uma lista de atividades práticas, oportuniza-se a eles um exame de si e a possibilidade de adequação ao que se narra como "modelo ideal", como se pode ver abaixo:

Compartilhe seu carro. 'Pratique a carona solidária e diminua a emissão de poluentes, levando pessoas que fariam o mesmo trajeto separadamente', recomenda o ambientalista Fábio Feldmann. Você vai se tornar o cara mais simpático da cidade ("Manual de Etiqueta Sustentável”, 2007, p.5).

Não há nada mais fora de moda que usar a mangueira de água para varrer a calçada, a chamada 'vassourinha hidráulica' [...] ("Manual de Etiqueta Sustentável”, 2007, p.8).

Muito luxo produz muito lixo ("Manual de Etiqueta Sustentável”, 2007, p.8).

Adquirindo produtos de boa qualidade, duráveis e realmente úteis, ajudamos a diminuir a quantidade de quinquilharias que viram sucata em pouco tempo. Você pratica essa ação? ("Manual de Etiqueta Sustentável”, 2010, pergunta 74).

É preciso fazer algo. E devemos fazer já ("Manual de Etiqueta Sustentável”, 2007, p.2).

Na hora de comprar um carro, faça um cálculo simples de qual o tamanho ideal de sua necessidade ("Manual de Etiqueta Sustentável”, 2007, p.5).

[...] Aproveite para avaliar com seus botões: será que você precisa mesmo de um freezer? ("Manual de Etiqueta Sustentável", 2007, p.7).

Pense antes de sair comprando tudo que aparecer pela frente ("Manual de Etiqueta Sustentável", 2007, p.11).

Pare e pense antes de descartar todos aqueles objetos que não interessam mais a você ("Manual de Etiqueta Sustentável", 2007, p.11). 
O pressuposto do uso de nossa razão no momento em que estamos envolvidos em atos de consumo articula-se, em uma relação de oposição decorrente do pensamento binário típico da modernidade, à desrazão, à emoção, ao impulso. A convocação para um tipo de consumo que se ocupa não apenas com a satisfação do desejo, mas também com o registro dos hábitos de compra, com o planejamento dos gastos, com o descarte responsável dos objetos, enfim, que prescreve práticas indispensáveis a serem incorporadas pelos consumidores que aspiram a se tornar do tipo 'consciente', acaba por legitimar a normalidade do consumo consciente, pois, como afirmam Rose e Miller,

\footnotetext{
Fazer com que as pessoas registrem coisas e as contem [...] é em si mesmo um modo de governá-las, um estímulo a que os indivíduos interpretem suas vidas de acordo com tais normas. Por meio de tais mecanismos, as autoridades podem influenciar e arregimentar os que estão distantes delas no espaço e no tempo, na busca de objetivos sociais, políticos ou econômicos, sem invadir a 'liberdade' ou a 'autonomia' delas - com efeito, muitas vezes, precisamente, oferecendo-se para maximizá-las ao transformar um hábito cego em uma liberdade calculada a ser escolhida (ROSE; MILLER, 2012, p.87).
}

O caráter pedagógico dessas informações que esclarecem e responsabilizam (AQUINO, 2011) permitem definir as práticas de sustentabilidade que os manuais da Editora Abril prescrevem como evidência de um esforço do governo em fazer emergir um consumidor autônomo, autogovernável, que tenha condições de dominar-se conforme o modelo ideal do consumo consciente. O que desejo sublinhar com isso é o modo como as práticas discursivas implicadas no enunciado "aprenda a comprar bem, para comprar sempre" nos posicionam como 'agentes' de transformações ambientais, sociais e econômicas ao mesmo tempo em que nos responsabilizam pelo futuro do planeta, da sociedade e da economia.

\section{DISCUSSÃO}

“O que é tido por verdadeiro se faz obedecer" (VEYNE, 2011, p.167). A construção discursiva do consumo consciente pressupõe não apenas um conjunto de enunciados que assim o definem, mas também um grupo de especialistas autorizados a falar, que, valendose de recursos de diagnóstico validados em nossa sociedade, formam uma expertise do consumo. Como sublinham Rose e Miller: 
"A linguagem de expertise desempenha aqui um papel importante, sendo que suas normas e valores parecem convincentes por causa de seu apelo a uma verdade desinteressada, e a promessa que eles oferecem de alcançar os resultados almejados" (ROSE; MILLER, 2012, p.49).

Assim, no exercício do governo, objetiva-se, sob determinado campo de saber, o indivíduo, e, na relação de poder pressuposta pelo saber exclusivo que se detém sobre o Outro, subjetiva-o, operando, assim, 'à distância', pela liberdade de escolha dos indivíduos. Nesse sentido, não apenas o Estado, mas também a empresa privada ou qualquer agente civil podem ser identificados como um 'perito', porque a autoridade que lhes é conferida o é pelas 'verdades desinteressadas' que professam em nome da felicidade e prosperidade dos indivíduos. De maneira que, "por meio da expertise, as técnicas autorreguladoras podem ser inculcadas em cidadãos que coadunarão suas escolhas pessoais com os propósitos do governo" (ROSE; MILLER, 2012, p.88). Nesse sentido, tenho afirmado que a Planeta sustentável, pelo saber que apresenta acerca do consumo e por meio dos especialistas convocados a falar sobre os modos mais adequados de consumir, deve ser entendida como parte da expertise do consumo que, na contemporaneidade, participa da constituição dos sujeitos. Uma expertise do consumo que trabalha para estudar a regularidade dos fenômenos decorrentes do hiperconsumo, tanto no que diz respeito aos impactos ambientais, quanto aos seus efeitos sociais e econômicos. Mas não somente para se conhecer os consumidores, mas, principalmente, para controlar os fenômenos populacionais em seu nível macro e micropolítico.

Dito de outra forma, o sujeito do consumo consciente emerge da visibilidade que lhe é proporcionada pela discursividade decorrente de uma expertise do consumo que se soma ao debate mais contemporâneo em torno das questões ambientais. Essa relação entre as noções de meio ambiente e consumo tem sido analisada por outros pesquisadores, com os quais dialogo aqui, na intenção de aprofundar esse argumento a respeito da visibilidade conferida, na cultura, aos sujeitos do consumo consciente.

No artigo "Lições de sustentabilidade em um jornal brasileiro", ao analisarem o suplemento "Nosso mundo sustentável", editado em um jornal gaúcho e outro catarinense, Kirchof, Wortmann e Bonin concluíram que o jornal "(re)inventa um tipo de sustentabilidade, que acomoda disputas comerciais muito próprias ao capitalismo contemporâneo às postulações mais comumente associadas ao ecologicamente correto" (KIRCHOF; WORTMANN; 
BONIN, 2011, p.118). Segundo esses autores, é possível verificar um alinhamento entre os usos que o capitalismo faz da sustentabilidade e a conduta sugerida pela lista de ações do cotidiano, notoriamente 'politicamente correta', que a sustentabilidade pressupõe. Assim, suponho eu, acomodam-se, não sem lutas, duas linhas de força do discurso que conferem visibilidade ao consumo consciente. Linhas aparentemente opostas - de um lado, o apelo ao consumo e, de outro, a regulação do consumidor pelo ideário da sustentabilidade - que conferem um caráter ambivalente ao alinhamento delas no interior na ordem do discurso do consumo consciente. A ambivalência não é uma exclusividade dos sujeitos do consumo, mas, como marca da cultura contemporânea, acaba por deixar suas digitais também sobre eles, pois, como explica Bauman:

\begin{abstract}
A situação torna-se ambivalente quando os instrumentos linguísticos de estruturação se mostram inadequados; ou a situação pertence a qualquer das classes linguisticamente discriminadas ou recai em várias classes ao mesmo tempo. Nenhum dos padrões aprendidos poderia ser adequado numa situação ambivalente - ou mais de um padrão poderia ser aplicado; seja qual for o caso, o resultado é uma sensação de indecisão, de irresolução e, portanto, de perda de controle (BAUMAN, 1999, p.10).
\end{abstract}

De fato, não apenas a noção de 'consumo consciente' pode ser considerada ambivalente, mas até mesmo a noção de 'desenvolvimento sustentável' implicada nessa discussão também o é. Como explica Sampaio, inspirada em Scotto, Carvalho e Guimarães (2007), "ainda que anuncie um futuro de oportunidades comuns, com maior equidade social e equilíbrio ambiental, ele se sustenta na crença em 'um desenvolvimento baseado no crescimento econômico, dentro de uma lógica concorrencial de mercado" (SAMPAIO, 2012, p.102). A autora ainda sublinha, nesse estudo, sua tese de doutorado intitulada Uma floresta tocada apenas por homens puros: ou do que aprendemos com os discursos contemporâneos sobre a Amazônia, que trata justamente desse caráter conciliador que permite o sucesso e a aceitação do termo 'desenvolvimento sustentável'. Com isso me permito pensar que a ambivalência do consumo consciente, uma verdade quase incontestável em nossos dias, compartilha de semelhante aceitação também por este mesmo motivo - o caráter conciliador, embora ambivalente - que pressupõe. 


\section{CONSIDERAC̦ÕES FINAIS}

Assim, se está correta a análise de Bauman, segundo a qual "[...] a economia líquido-moderna, centrada no consumidor, se baseia no excesso de ofertas, no envelhecimento cada vez mais acelerado do que se oferece e na rápida dissipação de seu poder de sedução - o que, diga-se de passagem, a transforma numa economia da dissipação e do desperdício" (BAUMAN, 2008, p.35), então, o consumidor consciente, aquele que pensa antes de agir e, supostamente, muitas vezes, deixa de comprar, faz emperrar a roda do capitalismo. Mas, ao mesmo tempo, compra-se demais a ponto de causar endividamento e restrição de crédito, ou a ponto de se esgotarem os recursos naturais envolvidos na produção; sem produção, não há consumo, também a roda do capitalismo emperrará. Com isso, acredito, finalmente, ter chegado ao ponto de maior aproximação do entendimento da ambivalência como marca dos sujeitos que vivem em uma sociedade de consumo.

Para esse aparente mal-estar provocado pelo ambivalente, pouco posso sugerir. Ele é marca de nossos tempos. Mas, quanto aos modos de governo a que estamos submetidos na condição de consumidores, como se pôde demonstrar aqui, preciso lembrar que, como nos esclareceu Foucault (2003), o poder é relacional. Onde há exercício do poder, há possibilidade de resistência. E é exatamente aí que vislumbro a desnaturalização do consumo consciente como uma forma de resistência. A adoção de estratégias que se valham desse exercício de desnaturalização em nossas práticas de educação ambiental é algo ao nosso alcance. Não podemos perder de vista que, antes de essencializar um tipo específico de consumo que se julga mais adequado aos objetivos econômicos contemporâneos, o que se está essencializando é o próprio consumo. É a verdade do consumo consciente que proponho desnaturalizarmos em nossas práticas de ensino na área da Educação e, em especial, a Educação Ambiental.

\section{NOTAS}

${ }^{1}$ Lê-se no site do instituto AKATU que ele surgiu no ano 2000, dentro do Instituto Ethos de Empresas e Responsabilidade Social. A missão da nova organização não governamental seria a de "mobilizar as pessoas para o uso do poder transformador dos seus atos de consumo consciente como instrumento de construção da sustentabilidade da vida no planeta". (Disponível em: http://www.akatu.org.br/Institucional/OAkatu. Acesso em: 12 abr. 2013).

${ }^{2}$ Os 12 princípios listados pelo guia são: 1. Planeje suas compras. 2. Avalie os impactos de seu 
consumo. 3. Consuma apenas o necessário. 4. Reutilize produtos e embalagens. 5. Separe seu lixo. 6. Use crédito conscientemente. 7. Conheça e valorize as práticas de responsabilidade social das empresas. 8. Não compre produtos piratas ou contrabandeados. 9. Contribua para a melhoria de produtos e serviços. 10. Divulgue o consumo consciente. 11. Cobre dos políticos. 12. Reflita sobre seus valores. (Disponível em: http://www.akatu.org.br/Temas/ Consumo-Consciente/Posts/Conheca-os-12-principios-do-consumo-consciente. Acesso em: 12 abr. 2013).

${ }^{3}$ Expressões como sustentabilidade, economia verde, papel, sacolas plásticas, clima, água, por exemplo.

\section{REFERÊNCIAS}

AQUINO, Julio Groppa. A governamentalidade como plataforma analítica para os estudos educacionais: a centralidade da problematização da liberdade. In: BRANCO,

Guilherme Castelo; VEIGA-NETO, Alfredo (Orgs.). Foucault: filosofia \& política. Belo Horizonte: Autêntica, 2011. p.195-211.

BARBOSA, Lívia. Sociedade de consumo. Rio de Janeiro: Jorge Zahar, 2004.

BAUMAN, Zygmunt. Modernidade e ambivalência. Trad. Marcus Penchel. Rio de Janeiro: Jorge Zahar, 1999.

COSTA, Marisa Vorraber. Mídia, magistério e política cultural. In: COSTA, Marisa Vorraber (Org.). Estudos culturais em educação: mídia, arquitetura, brinquedo, biologia, literatura, cinema... Porto Alegre: Editora da UFRGS, 2004. p.73-91.

FEATHERSTONE, Mike. Cultura de consumo e pós-modernismo. Trad. Júlio Assis Simões. São Paulo: Studio Nobel, 1995.

FONSECA, Márcio Alves. Michel Foucault e a constituição do sujeito. São Paulo: EDUC, 2011. FOUCAULT, Michel. Tecnologias del yo y outros textos afines. Barcelona: Paidós, 1991.

FOUCAULT, Michel. O sujeito e o poder. In: DREYFUS, Hubert; RABINOW, Paul. Michel Foncault: uma trajetória filosófica - para além do estruturalismo e da hermenêutica. Rio de Janeiro: Forense Universitária, 1995. p.231-249.

FOUCAULT, Michel. A ordem do discurso. Aula inaugural no Collège de France, pronunciada em 02 de dezembro de 1970. Trad. Laura Fraga de Almeida Sampaio. São Paulo: Edições Loyola, 1996.

FOUCAULT, Michel. Microfísica do poder. 18.ed. Rio de Janeiro: Edições Graal, 2003.

FOUCAULT, Michel. Nascimento da biopolitica. Curso dado no Còllege de France (1978-1979). Trad. Eduardo Brandão. São Paulo: Martins Fontes, 2008.

KIRCHOF, Edgar; WORTMANN, Maria L.; BONIN, Iara T. Lições de sustentabilidade em um jornal brasileiro. Revista Eletrônica do Mestrado em Educação Ambiental, Rio Grande/RS, v.27, p.116-128, jul./dez. 2011.

LARROSA, Jorge. Tecnologias do eu e a educação. In: SILVA, Tomaz Tadeu (Org.). O sujeito da educaşão: estudos foucaultianos. Petrópolis: Vozes, 1994. p.35-86

ROSE, Nikolas; MILLER, Peter. Governando o presente. São Paulo: Paulus, 2012. (Coleção Biopolíticas).

SAMPAIO, Shaula M. "Uma floresta tocada apenas por homens puros...” Ou do que aprendemos com os discursos contemporâneos sobre a Amazônia. 236f. 2012. Tese (Doutorado) - Universidade Federal do Rio Grande do Sul, Programa de Pós-Graduação em Educação, Porto Alegre, 2012.

VEYNE, Paul. Foucault: seu pensamento, sua pessoa. Trad. Marcelo Jacques de Morais. Rio de Janeiro: Civilização Brasileira, 2011. 


\section{MANUAIS ANALISADOS}

Manual de Etiqueta: 33 dicas de como enfrentar o aquecimento global e outros desafios da atualidade. São Paulo: Abril, 2007.

Manual de Etiqueta: 120 ideias para enfrentar o aquecimento global e outros desafios da atualidade. São Paulo: Abril, 2010. Disponível em:

http://planetasustentavel.abril.com.br/manual2010/. Acesso em: 12 abr. 2013.

Manual de Etiqueta 3.0: 65 dicas para enfrentar o aquecimento global e outros desafios da atualidade. São Paulo: Abril, 2011.

Manual de Etiqueta: novas ideias para enfrentar o aquecimento global e outros desafios da atualidade. São Paulo: Abril, 2012.

Recebido: 25/04/2013

Aprovado: 15/01/2014

Contato:

Universidade Federal do Rio Grande Instituto de Educação.

Avenida Itália Carreiros

Rio Grande | RS | Brasil

CEP 96.203-000 